\title{
DAMAGE DIAGNOSIS IN CONCRETE DAMS WITH PRESENTED EXPANSIVE DAMAGE BASED ON MEDICAL PROPAEDEUTICS
}

\author{
F. Pardo-Bosch, Ph.D. ${ }^{\text {a }}$, and A. Aguado, Ph.D. ${ }^{\text {b }}$ \\ ${ }^{a}$ Postdoctoral Researcher, Dept. of Civil and Environmental Engineering, Polytechnic Univ. of \\ Catalonia, UPC, Jordi Girona 1-3, 08034 Barcelona, Spain.e-mail: francesc.pardo@upc.edu \\ (corresponding author) \\ ${ }^{b}$ Full Professor, Dept. of Civil and Environmental Engineering, Polytechnic Univ. of Catalonia, UPC, \\ Jordi Girona 1-3, 08034 Barcelona, Spain.e-mail: anotnio.aguado@upc.edu
}

\begin{abstract}
The maintenance of dams is crucial given their social, environmental and economic relevance. However, more than $40 \%$ of the world's dams are over 40 years old. Furthermore, due to their ageing, damage such as cracks, leaks and remaining movements have the potential to affect their serviceability and safety. This paper provides dam maintenance technicians with a methodology that first provides a diagnostic hypothesis, as maintenance work can only be considered if the source of the problem is known. The methodology provides technicians with tools for making decisions to ensure the short and long-term sustainable management of a fundamental resource for societies. The analysis uses a transversal approach broken into three stages: study of the structure's "clinical" history, field inspection and analysis. These tasks are described from a technical point of view with a range of examples and graphs to demonstrate their practical usefulness and to facilitate implementation.
\end{abstract}

Keywords: Diagnosis, dams, damage, inspection, concrete, expansion.

\section{Introduction}

The United Nations Environment Programme (UNEP, 2007) considers large dams to have played a major 
role in the socio-economic transformation of many countries. Dams are civil works that have been constructed for over 4500 years (Schnitter 2000). Their main functions are water supply for humans, irrigation, year-round flood control, power generation, navigation, fishing and even leisure. One of the latest major environmental contributions of dams has been hydropower. The growing willingness to exploit clean and renewable energy sources that do not emit $\mathrm{CO}_{2}$ into the atmosphere has consolidated hydropower, which has been around since the ancient Greeks. According to the International Commission on Large Dams (ICOLD), the main drawback of dams is the obvious environmental and social impact caused by their construction, in addition to the large financial investment required (ICOLD, 1997).

Given this situation and the fact that society cannot do without the benefits provided by dams, the utility of dams already in operation must be maximized. However, these structures, just like human beings, are subject to damage over time that can vary in form, mode and origin. When they become aged and enter a phase of what Ellingwood and Tekie (2000), Diéz-Cascón and Bueno (2001) and Kalantarnia et al. (2016) call progressive deterioration, great lengths must be taken in the regular maintenance to proactively manage the risk associated with the aging of the dams. ICOLD (2011) estimates that more than $40 \%$ of the world's dams are over 40 years old and therefore in this phase of progressive deterioration. To be effective, maintenance actions must be based on a diagnosis that explains the cause of the damage, as occurs in medicine, where the diagnosis is of utmost importance for treatment choice (Morgan and Engel, 1971; Laín, 1982; Friedman, 2001; and Carter et al., 2005).

Although damage diagnosis is undoubtedly one of the biggest challenges for engineering in the 21st century, there is a glaring lack of research on it for dams. Determining the cause of damage is often given very little importance by technicians, who make decisions based on their expertise and intuition. They put most of their faith in laboratory testing and numerical studies, which should only be seen as complementary tools, as occurs in medicine (Balsells, 2010). Generally, the cause of major problems requiring dam repair is identified to mitigate future damage. However, as Andriolo (2002) points out, technical reports on dam maintenance exist that show repairs being undertaken without seeking to discover the origin of the problems, or that any investigation that did take place did not determine the causes of the problems. 
Surprisingly, then, diagnosis has received minor attention from the technical community specializing in dams (as is discussed in Section 2). The nonexistence of a referential framework has meant poor optimization in the selection of maintenance actions (in terms of economic investment and the reduction of risk levels) (Pardo-Bosch and Aguado, 2015). This is a problem in the current times of relative financial hardship. Such times are precisely when the most benefit can be gained from each and every investment in public infrastructures (Pardo-Bosch and Aguado, 2016).

For this reason, this paper's main objective is to organize the activities (basically of reasoning) that technicians should perform to solve the mysteries that arise in determining the cause(s) of damage to the structural units forming a dam. The sequence of activities recommended is inspired and based on medical propaedeutics, the theory used in medicine to explain what procedures the doctor should perform to detect signs or symptoms of damage as well as to collect preliminary data about patients using different techniques.

This paper does not propose any new techniques or calculation methods. The aim is simply to provide a new perspective on the physical examination of dams, this being the basis of the argument put forward in this paper. Laboratory testing and numerical studies are pushed back to a later stage (which follows the stages treated in this paper) and are only used to confirm or discard the diagnostic hypothesis. This approach saves valuable resources (and not only economic ones) that could be used for other purposes. The proposed methodology has not been developed from the theory found in the literature, although this knowledge has been taken into account. The methodology has been conceived mainly based on practical knowledge acquired through technical visits to more than 25 concrete dams scattered throughout different countries. Although the approach in this paper is applicable generally, because the authors have extensive expertise in concrete dams with expansive reactions, the examples presented concern this pathology.

\section{Review of literature}

This section reviews how the technical community has to date handled the study of major damage that can affect a dam in an ordinary period of operation. 
Over the last 50 years, ICOLD has published 147 bulletins, although only four of these bulletins concern the study of damage: B.71-Exposure of Concrete Dams to Special Aggressive Waters (ICOLD, 1989), B.79-Alkali-Aggregate Reaction in Concrete Dams (ICOLD, 1991), B.93 - Ageing of Dams and Appurtenant Works (ICOLD, 1994), and B.107 - Concrete Dams - Control and Treatment of Cracks (ICOLD, 1997). While all of them review historical cases, none explicitly propose a methodology of diagnosis for determining the origin of the damage in future studies. Even so, they do provide some interesting contributions on which to base this type of methodologies.

The most outstanding work in ICOLD is carried out by the Italian Commission on Large Dams (ITCOLD), which studies dam diagnosis because it is an issue that in recent years has not attracted the attention of the scientific-technical community (ITCOLD, 2012). Their paper focuses on using mathematical models as a support tool for the diagnosis. However, there is a short introductory part that situates the diagnostic in the bigger picture, stating that its success requires objective criteria obtained from a series of regulated activities that allow understanding what is happening in the structure. These activities include visual inspection, characterization of the material constituting the joint dam-foundation-reservoir, static monitoring and dynamic monitoring.

Some research deal with the diagnosis of dam damage in other contexts. In these works, there are two very distinct trends in systems for determining the origin of the damage affecting the dams. For instance, Wu and Qie (2002), Peyras et al. (2006) and Xu (2011) present informational systems that support this decisionmaking. These systems use large databases and allow the technician to determine the origin of the damage without having to make an expert judgement. These models interrelate expert knowledge (through the database), artificial intelligence, numerical analysis and computing power. This combination makes them very interesting tools, which are normally associated with risk analysis and not diagnosis because no assessments are made about what may have caused the damage. The main function of the system is prognosis.

On the other hand, authors such as Fargier et al. (2012) propose more classical diagnostic systems, which entail studies of historical information, geological studies, reviews of maps and topography, visual 
inspections, morpho-dynamic studies and specific studies. These activities should allow technicians, based on their judgement, to determine the causes of the damage. The drawback of this methodology is that it is developed to study dams or dykes of loose materials. In addition, to give dam technicians practical guidelines, detailed instructions must be provided on how each of the tasks is to be performed and, above all, on how the information collected in the different stages should be treated.

Table 1 illustrates the principal causes of damage that can affect an operational concrete dam. According to New York State-Department of Environmental Conservation (1987), Aguado et al. (1996a), Bureau of Reclamation (1997), ITCOLD (1999), Groza and Toda (2011) and British Columbia (2011), these causes are expansive reactions, acid attacks, abrasive erosion, cavitation erosion, Cyclic freezing and thawing, thermal effects, actions (deformation) of the rock mass and uplift pressure. For each cause, the table lists the principal signs of damage, their typical location and the main consequences.

\section{[Table 1 near here]}

\section{The diagnosis and its stages}

In civil engineering, as in humans, structural damage can be understood as the structure's failure to fight off internal or external elements attacking it. Using this analogy between humans and structures (two kind of "living beings"), Feinstein (1967) (despite its age, a very frequently referenced work that Talavera and Rivas-Ruiz (2012) say all sensible doctors should know and apply) states that the diagnosis in engineering, as occurs in medicine, must have two clear objectives: first, to define the cause of the damage; and second, to determine the consequences that the damage can cause in the element that suffers from it. Thus, the diagnosis must be understood as a systematic analysis of physical signs observed at the dam. The results should be compared first to the normal states as established by engineering and second to the original state of the dam. Great technological advances, both in laboratory and numerical studies, cannot replace the diagnosis because they are solely a complement to it, just as proposed by medical propaedeutics.

To ensure a complete process, a sequence of activities is proposed that can be divided into two phases, as 
shown in Figure 1, based on the expertise acquired and medical propaedeutics. The process starts with damage detection, which entails the following activities:

-The first phase (the subject of this paper), which lasts a few weeks, consists of damage detection, study of the clinical history, field (dam) inspection, first cabinet works and definition of the first diagnostic hypothesis.

-The second phase, which has been widely covered in scientific-technical forums and which can last for months, entails laboratory tests, numerical models, verification of the diagnosis and definition of the forecast.

[Figure 1 near here]

\section{Study of the clinical history}

This stage involves collecting all the documentation for contextualizing the investigation. The goal is to learn about the structure. This study is divided into two phases: historical documentation and auscultation data.

The historical documentation phase entails exploring the history of the dam, from initial planning to operation, including construction. This information provides valuable assistance as it facilitates ongoing examination by different technicians and encourages investigation. The best way to start a study of the structure is to review the basic technical characteristics of the dam. Deepening the study of the structure requires examining and considering all isolated information that may appear across various documents. This review might reveal historical particularities that may bear relation to the pathology under investigation. Small details can be important in the forming of an opinion. Such information, for example, was fundamental for diagnosing the Camarasa Dam (Blanco et al. 2015). In undertaking this phase of the study, technicians may want to review technical reports (particularly dam books), construction books, plans of the dam (plans, profiles and details), old photographs, rehabilitation projects, articles in journals or conferences, etc. Reviewing documents on other contemporary structures is also important. 
Studying the auscultation data collected by the monitoring system allows describing how the dam's behavior has evolved over time. In a concrete dam, there are many variables measured over time (ITCOLD, 1988). Because of this monitoring activity, a lot of data is collected, making its analysis and management very complicated. To optimize time in this phase, the study is usually limited to examining only data on horizontal and vertical movements. ICOLD (2000) and Lombardi et al. (2001) state that the most important and most accurately measured monitorable parameters in a dam are the movements. Any important event occurring in the dam body or its foundations causes a global response from the structure, which is reflected in the registered movements. The monitoring and analysis of these measures should permit distinguishing between recoverable cyclic movements (from hydrostatic thrust and thermal action) that do not usually represent a problem and the remaining movements, or non-recoverable ones. The remaining movements are a consequence of some abnormal phenomenon. The movement of foundations, slopes and expansive reactions are the main causes of these movements. Observing the trend of non-recoverable movements does not require many measurements. Figure 2 illustrates three different levelling movements of a concrete dam. Regardless of the number of measurements used (one, two or twelve per year) to make the representation, from 1966 (month 0) until 2008 (month 504), the dam grows between 47 and $60 \mathrm{~mm}$ according to the measured block, which raised the alarm and caused a detailed study of the dam to be undertaken in this case.

\section{[Figure 2 near here]}

\section{Field (dam) inspection}

A field or visual inspection of the structure is the physical examination of the whole dam and its surroundings done personally by the technician. This technique, which may seem basic, is very important because it allows discovering structural alterations and abnormal signs (see Table 2), which in some cases cannot be detected by other monitoring systems. During the field inspection, a series of complementary activities should be performed (collection of samples, taking photos, etc.). 
[Table 2 near here]

\section{Geological formation}

An inspection of the quarry where the rock came from must be performed to evaluate whether the geological characteristics of the aggregate might be a source of problems. The open front of a quarry is exposed to external elements against which the rock mass can do little to defend itself. The rock's defenselessness allows chemical processes arising from its geological characteristics to occur. Thus, its degradation is a magnificent mirror of the aggregate that was extracted from it. If the rock of one the fronts shows signs of alteration, it is very likely that the aggregate of the dam contains minerals that, under certain conditions of exposure, will react with the water or the cement paste compounds giving rise to expansive reactions.

Figure 3 shows two different quarries that were used to build the same dam. The rock from the first quarry (Figure $3 \mathrm{~b}$ ) has a high chemical reactivity due to its content of sulfur compounds that has caused an expansion of the concrete. In contrast, the rock from the second quarry (Figure 3c) does not have any reactive capacity, and its concrete is perfectly conserved.

\section{[Figure 3 near here]}

The main purpose of the study of the abutments is to determine if their behavior can generate a terrainstructure interaction that affects the conservation of the dam. The abutments generate some horizontal restrictions in the dams not found in the vertical plane. The relative motion in discontinuity, weathering of the rock or expansion of existing material in the joints can cause an alteration in the abutments' system of acting forces on the structure that can produce negative effects on it. If the structural effects are caused by the weathering of the rock, the force is not uniform at different heights, and the compression exerted by the abutments on the dam is larger the closer the rock is to the crest. The top of the abutments in the ground that is exposed to natural degradation for more time means that the deterioration of the rock and its 
expansion is greater than that occurring closer to the foundation. In addition, the stiffness of the dam is greater at the base of the dam than at the top, making it easier to resist any action at the bottom of the structure than at the top of the blocks. This means that the expansion of the abutments at the top of the dam may be more significant. As a result of the terrain-structure interaction, in areas close to the crest (on both faces), longitudinal fissures may appear at a horizontal angle of between $0^{\circ}$ and $45^{\circ}$, depending on the existing slope in the dam-terrain contact, as can be seen in Figure 4.

\section{[Figure 4 near here]}

\section{Annexed structures}

This stage examines possible non-structural damage to constructions in or near the dam that are independent of the dam. The objective is to assess whether the one cause might be responsible for the damage to such structures and the dam. According to Aguado et al. (1996a), in Europe, between 40 and $50 \%$ of dam failures are owing to the type of material used or construction errors. As it is likely that the dams and their surrounding structures were built using similar techniques and materials (cement, aggregates, water, etc.), the damage detected may have the same cause.

Non-structural cracks appearing early on, caused by either retraction (longitudinal fissures) or by shrinkage (map-cracking), should not represent major problems. On the other hand, cracking (structural or otherwise) that appears at an advanced stage of operation is normally the result of an expansive concrete reaction. Typically, in these cases, map-cracking occurs. This type of cracking can manifest itself earlier on and

possibly more significantly in auxiliary structures than in the dam because such structures are subject to relatively favorable conditions of confinement, in addition to having slender geometries.

Figure 5 illustrates an example of an adjoining structures at a dam with marked cracking that helped determine that the concrete contained reactive aggregates. This image shows the cracking (mapped and longitudinal) of the teeth at the foot of a (heavily reinforced) gravity dam affected by an internal sulfuric attack. 


\section{[Figure 5 near here]}

\section{Dam body}

At this stage of the study, the aim is to detect the pathological signs that may occur in the crest, paneling, spillways, galleries and wells. The main signs include remaining movements, leaks, moisture stains, mapcracking and any other sign of concrete deterioration.

At the crest, especially in straight plan dams, it is relatively easy to detect both horizontal and vertical remaining movements, which are a clear indication of abnormal behavior in the dam or its foundation. In arch dams, the curvature and the transmission of loads in the longitudinal axis hinder their observation, although they can also be detected. If very notable, the movements can be detected by the variation of the openings of concrete joints or by the misalignment of concrete blocks, as shown in Figure 6a of a 150-m high gravity dam. If the movements are small, the best way to detect them is through the misalignment of slender linear elements, such as rails or handrails.

\section{[Figure 6 near here]}

The walls and spillways are where the largest expanses of visible concrete are found. In addition, these are the areas most exposed to external actions, making them the place to detect pathological signs more easily. Where the reservoir has dropped, the alternation in the state of humidification allows some damage to be detected relatively easily, especially cracks. Figure $6 \mathrm{~b}$ shows the downstream face of a dam with sealed longitudinal fissures.

In contrast, the downstream face and spillways are easier to study in detail. First, because their entire surfaces are visible to the human eye and, second, because in some cases they can be accessed from a gallery or abutment. Figure 7 shows an example of a damaged downstream face, the spillway of a Catalan dam. This image clearly shows both mapped and longitudinal fissures, in addition to newly formed material seeping from the cracks. Although the cracks are the main indicators in the above examples, there are other 
signs of deterioration.

\section{[Figure 7 near here]}

The galleries allow access to the interior of the dam. From them it is easy to observe the state of the structure and review all its branches. Areas just a few meters apart can present considerably different signs of physical deterioration, which can be a key observation for the diagnosis. If signs of damage are located spatially, in addition to matching it with the signs appearing in the walls, possible particularities of construction may be verified later, which was instrumental in the diagnosis of one dam in particular. This dam, at $1339 \mathrm{~m}$, has a gallery with a branch parallel to the axis of the river that gives access to the downstream face. The branch is divided across its central axis by a vertical joint of $\mathrm{J} 9$ concrete. The concrete plan (Figure 8a) reveals that at this height the J9 joint separates a block made with expansive concrete from one made with good concrete. Figure $8 \mathrm{~b}$ shows the branch of the gallery in question. The right side is in very good condition (Figure 8c), while the area on the left (where the expansive concrete is according to the concrete plan) shows considerable surface deterioration (Figure 8d). Detecting this meant that the theoretical and visual observations could coincide. Thus, it was confirmed that the main cause of deterioration was an expansive reaction of the concrete.

\section{[Figure 8 near here]}

Cracks appear systematically in the upper galleries. Their appearance is usually noticeable and has a preferential orientation. The cracking may be straight, extending only along a single side of the gallery, or oblique, which means that it often starts in the gable of one of the walls, shifting position until it ends up in the gable of the opposite wall if the gallery is long enough. Oblique cracking is normally induced by differential movement between blocks accompanied by a dragging phenomenon in the vertical joints.

Finally, the state of the wells where the pendulums are installed, either from the galleries or the crest, must 
also be checked. This test is the only way (except for expensive core drilling tests) of determining the state of the concrete in the center of a block.

\section{Mobile elements}

This section deals with the important task of inspecting the moving parts, basically sluices and turbines. In such elements, special attention must be paid to jams and changes in the geometry of their openings. Operational problems may indicate a change in the volume of the adjacent concrete. One of the clearest indicators is the gates becoming increasing difficulty to open and close. One of the biggest problems that can occur to a dam is the jamming of a gate. The inability to open it when the hydraulic conditions require it could cause a catastrophe. Concrete cracked from the breakwater where the gate of a dam rests is shown in Figure 9. In this dam, when problems emerged in moving the floodgates, rehabilitation work was carried out that entailed installing anchors to limit the expansive capacity of the concrete.

\section{[Figure 9 near here]}

\section{First cabinet works}

Once all the tasks entailed in the physical examination of the structure have been completed, the analysis is undertaken, which should clarify any doubts the technician has regarding the origin of the damage. This stage aims to match the movements with the observed indicators. The first step is to determine whether the abnormal behavior of the structure is generalized or localized. Second, an attempt is made to predict the evolution of the movements.

\section{Is the abnormal behavior generalized or localized?}

To determine the origin of the damage, it is important to know if the damage alters the behavior of the whole or only a part of the structure. If the behavior is uniform and the damage is distributed throughout the whole structure, the dam is probably not affected by an external action (which nearly always have a 
local or less generalized effects). Therefore, the origin of the damage must lie in the construction itself. If, on the other hand, the damage is localized and, in addition, there are movements that differ sharply from the rest of the structure, the cause is probably external.

To find out if the problem that the dam suffers is generalized or localized, a method is presented (although others that are equally valid can also be developed) that establishes two relationships between the remaining movements registered and the geometry of the dam blocks. The first is between the collimation movements (C) and the slenderness of the blocks $\left(\mathrm{j}=\mathrm{h}^{2} / \mathrm{b}_{\mathrm{eq}}\right)$, and the second is between the levelling movements (N) and the height of the blocks (h). If a clear correlation exists between movements and geometry, the problem is likely to be widespread. If, on the other hand, there is no correlation, a localized problem is probably the cause.

These relationships are obtained from a simplified geometrical analysis of compatible deformations that may occur in a block. Both levelling and collimation movements can be expressed as a function of the geometric parameters of the structure and the specific deformation of the walls (assuming a compatible linear distribution in the interior of the block). Thus, as the block of a dam is recessed in the floor (bracket type behavior) and imposes a constant deformation gradient along its height, movements in the crest can be defined according to the equations ec. 1 and ec. 2.

$$
N=\frac{\varepsilon_{1}+\varepsilon_{2}}{2} h \quad[1] \quad C=\left(\varepsilon_{1}-\varepsilon_{2}\right) \cdot \frac{h^{2}}{b_{e q}}
$$

Where $\varepsilon_{1}$ is the deformation in the downstream face, $\varepsilon_{2}$ is the deformation in the upstream face, $h$ is the block height, $b_{M}$ is the major base of the block, $b_{m}$ is the minor base of the block and $b_{e q}$ is the equivalent block base (ec. 3)

$$
b_{e q}=\frac{\left(b_{m}-b_{M}\right)}{\frac{b_{m}}{\left(b_{m}-b_{M}\right)} \cdot \ln \left(\frac{b_{m}}{b_{M}}\right)-1}
$$

The theoretical basis of this relationship was proposed by Martínez Roig et al. (1991) in a paper examining the possible causes of the anomalous behavior of the Graus dam. In this case, to not complicate the calculations, $b_{e q}=2 b_{M}$ is used, which is not entirely correct, although it is acceptable for an initial estimate. 
Carrying out this analysis requires at least three blocks representative of the recorded movements and a clear definition of the blocks' geometric characteristics. Before comparing the geometry with the movements on a graph, the height and slenderness of all blocks must be standardized with the height and the slenderness of the block for which the greatest movements were recorded. Also, the reported movements must be standardized with the values of the block for which the greatest movements were recorded. In Section 8 , an example of this analysis is illustrated in a case study.

\section{Interpretation of the movements and prediction of their evolution}

This task's objective is to determine the timeframe for the pathological process and make a prediction about how it will evolve. This entails attempting to fit a curve $z$ to the registered movements. This allows determining the approximate maximum magnitude of the movements and when it will occur.

If there is a reasonable set of data (40 years), the analytical model proposed by Aguado et al. (1998) can be used to predict the evolution of movements. This model uses an exponential function, equation ec. 4 , to fit a mathematical equation that satisfactorily represents the abnormal movement of structures. The basis of this model was developed to study the remaining movements observed in the crests of gravity dams affected by sulfidic reactions. It can also be used to analyze any type of dam movements, regardless of the source of the damage.

$$
z=A+B\left(1-e^{-\left(\frac{t}{C}\right)^{p}}\right)
$$

Where $A$ is the value of the ordinate at the origin, $B$ is the range of variation of the curve in order, $t$ is the time, $C$ is the value of the abscissa for which there is a turning point for curves with values of $p$ greater than 1 and $p$ is a parameter that gives the shape of the curve. Parameters $A, B, C$, and $p$ are obtained thanks to a statistical adjustment by least squares. If a curve is found that fits the registered movements (a correlation index of over 0.9), an order of reasonable magnitude of the evolution over time and the extent of these movements in time can be obtained. These predictions, which should be understood as such and not treated as infallible, allow technicians to orient the rehabilitation or maintenance work with some notion of what 
awaits them in the short term.

Figure 10 illustrates (with the dashed line) the adjustments made for the collimation movements of concrete in a dam (data from 2010). Figure 10a shows the different adjustments made for the one block (4), depending on the value of the variable $C$. Figure $10 \mathrm{~b}$ shows the adjustments made for all the blocks with 350 months as the value of $C$.

\section{[Figure 10 near here]}

These graphs reveal that the tendency of the movements is that they will keep rising, at least for some years (ten, approximately), until reaching a maximum collimation movement (base C3) of approximately 250 $\mathrm{mm}$. However, note that any change in the diagnosis of this dam (Campos, 2012) could modify these initial forecasts.

\section{Initial diagnostic hypothesis}

The end of the first phase of the study entails identifying the source of the damage, which should enable coming up with the initial diagnostic hypothesis. This section aims to help the engineer, particularly those with less experience, to properly manage the information collected at the different stages so they can achieve their goal efficiently.

As explained in Section 2, the actions that can cause significant damage to a concrete dam include expansive reactions, acid attacks, erosion by abrasion, erosion by cavitation, freeze-thaw cycles, thermal effects, actions (deformation) of the rock mass and negative pressure. Other actions that could affect dams include design flaws (own weight, hydrostatic thrust, thrust/impact of ice, etc.) and actions caused by extraordinary phenomena outside the realm of the structure's ordinary operation (earthquakes, extraordinary waves, etc.), which thus have not been taken into account in this section. The summary table in figure 11 aims to help technicians identify the cause of the damage by guiding their reasoning via the identification of the most relevant damage, i.e., cracking (mapped and longitudinal), remaining movements and surface degradation 
of concrete. Via the approach developed in this paper, a framework of symptoms comes to tell a clear story. Starting with the main signs of damage, a series of concepts and questions lead the technician to determine a pathological action, which should therefore be considered the main cause of structural dysfunction. This symptom framework obviously does not reveal all the cases or types of conditions that a concrete dam may have, but it does attempt to collect the most significant phenomena.

[Figure 11 near here]

All hypotheses require establishing a cause and effect relationship between the pathology, the structural behavior and the damage. If this cause and effect relationship cannot be found, the pathology is secondary and co-exists with another which is the main cause of the damage.

If the initial diagnostic hypothesis is accepted, then either the second phase of the diagnostic process (laboratory tests and numerical model studies) is initiated, or, where the diagnosis is found to be sound and there is an urgent need to repair the damage, corrective measures can be taken.

\section{Case studies}

The practical feasibility of this diagnosis methodology has been demonstrated with the study and diagnosis of various dams. By way of example, this section briefly describes the diagnosis of a concrete buttress dam completed in 1955 (Figure 12a), with an A section (Figure 12b), a maximum height from the foundation of 31 and a crest of $487.4 \mathrm{~m}$ in length, located in the north of Spain. This dam creates a reservoir of $72 \mathrm{hm}^{3}$ over an area of $869 \mathrm{hm}^{2}$. A particularity of this structure is that it is covered by stonework, which obscures the exterior state of the concrete from view. Over the years, certain indicators of damage have appeared that warranted undertaking a detailed study of the dam.

[Figure 12 near here] 
Historical documentation revealed that while a range of conservation and maintenance work had been carried out on the dam, none of these actions had stemmed the advance of the damage, which basically consisted of remaining movements that were in the vertical plane and slightly more towards the downstream face, as well as the presence of many cracks. During the physical examination of the inside of the dam buttresses, the dam was found to have both map and longitudinal cracking, with more on the upstream than the downstream face. In addition, calcium carbonate was found in these fissures and the concrete joints (Figure 13, which was taken from point "p" of Figure 12b on the ceiling of the gallery).

\section{[Figure 13 near here]}

To determine if the pathology was general or localized, the formula for the relationships set out in Section 6.1 was used. Four representative blocks were chosen for study: V, XII, XVIII and XXIV, situated on the ground as shown in Figure 12a. The geometric characteristics of the four blocks were very similar, as they all had the same profile but were of different sizes. Table 3 lists the geometric characteristics of the blocks studied, the registered movements and the standardized relationships required to create the graph. Each of the selected blocks had levelling $(\mathrm{N})$ and collimation $(\mathrm{C})$ bases with separate numbering.

\section{[Table 3 near here]}

Note that XII is the block with the greatest movement and height, and, consequently, the largest base values. This means there is a correlation between the geometry and movements. Note also that the collimation movements, even when negative (the dam moves downstream), give a positive normalized relationship. The graph in Figure 14 shows a comparison of the normalized values. Measured values of levelling (year 2010) are compared against the heights of the blocks in Figure 14a, while measured values of collimation (year 2010) are compared against the thinness of these blocks in Figure 14b. 
[Figure 14 near here]

As the two graphs show (it is more obvious in the first), there is a correlation between the movements and the geometry of the blocks. Thus, the effect the blocks suffer from is independent of their location, and the difference in the measured values corresponds only to the geometric differences. Therefore, the structure suffers a generalized pathology.

This diagnosis rules out a problem of ground-structure interaction in the area where the dam is anchored. It also rules out the foundation as the cause because in this case all the blocks would experience a similar movement, regardless of their geometry. Therefore, in this case, the cause of the problem is the material (concrete).

With this information, the technicians used the summary table in Figure 11, starting with "fissures". From this point, they could follow two different paths that lead to the same diagnostic hypothesis. The first option was the path created by mapped fissures, uniform remaining movements and newly formed material. Alternatively, the second option was the path created by longitudinal (horizontal) fissures, uniform remaining movements, collimation downstream movements and the newly formed material, the point where both paths converge. Thus, the origin of the damage was determined to be an expansive reaction. As no aggregate reagent was found, the hypothesis could be ruled out that the slight volume increase in the concrete of the dam was due to a slight expansion owing to a delayed reaction of free lime immersed in the concrete mass with water filtered by the stonework. Although this is not a normal reaction, it has been demonstrated in studies by Gonnerman et al. (1953) and Chatterji (1995), which show there can be a delayed expansion from subsequent hydration of free lime contained in cement. Gonnerman et al. (1953) assumes, furthermore, that this expansion can go on for years, even when the concrete is saturated. There was a high level of free lime in the cements of the 1950s. Maybe even as high as 5\%, according to Johansen (1977) and Calleja (1980). A hypothesis was consolidated after performing the relevant laboratory tests in the second stage of the diagnostic process. 
Despite this slight expansion, in 2009 the dam was in a good state of repair, so it was not necessary to undertake anything beyond the ordinary maintenance carried out in accordance with the sound judgement of the dam's technicians.

\section{Conclusion}

This paper presents a diagnostic methodology for determining an initial hypothesis regarding the origin of major damage that can affect an operational concrete dam. The methodology is eminently practical and is aimed at technicians responsible for the maintenance and upkeep of hydraulic works, although by no means have scientific fundamentals been cast aside. This tool remedies an historical knowledge gap caused by the fragmented approach with which the subject has been treated and the lack of attention this topic has received in the literature by the scientific-technical community, which has focused mainly on laboratory studies and numerical models. Such tools are much needed but belong in the stage of confirming the diagnostic hypothesis.

As argued in this paper, the best way of knowing what is happening in a structure is to study it directly, which saves both time and money. For this reason, the methodology put forward is exhaustive and proposes the analysis of various elements in a staggered and transversal manner. The sequence of activities proposed allows technicians of operational dams to determine the indicators necessary for establishing the initial diagnostic hypothesis. The definitive decision on the initial diagnostic hypothesis is achieved in a simple and intuitive way using the summary in Figure 11 that collects and synthesizes the different conclusions that the technician has obtained through analyzing the pathological signs. This framework is designed to distinguish between the signs of the main pathologies that can appear during the operational phase of a concrete dam as set forth in the technical literature. The paper refers to real examples to facilitate comprehension and applicability. Moreover, the practical feasibility of the tool has been demonstrated with the study and diagnosis of a Spanish dam.

This methodology has the potential to optimize processes from a technical (knowledge management in the one institution) and an economic point of view (prioritization of maintenance spending), with diagnoses 
carried out in one dam assessed for potential adaptation to another.

\section{0.- Acknowledges}

This work has been developed thanks to the projects BIA2010-20913-C02-02 and BIA2013-49106-C2-1-

$\mathrm{R}$ of the Ministerio de Ciencia e Innovación of Spain and also thanks to the support received over the years from Endesa Generación, Acciona Energía and Iberdrola Generación.

\section{1.- References}

Aguado, A.; Agulló, L.; Fdez-Canovas, M.; Sallas, J.M.; (1996a). "Diagnóstico de Daños y Reparación de Obras Hidráulicas de Hormigón". Colección Monografías: 19. Colegio de Ingenieros de Caminos, Canales y Puertos. Madrid, 285 p.

Aguado, A.; Agulló, L.; Casanova, I.; López, C. M. (1998). "Estudio de fenómenos expansivos en presas de hormigón. De la micro a la macro estructura". Comité Español de Grandes Presas. Premio José Torán, $103 \mathrm{p}$.

Andriolo, F. R. (2002). "Patología de las presas: sintomatología, diagnóstico y terapia. General Report". Proceedings of the 1st International Congress on Dam Maintenance and Rehabilitation, Madrid,p. 629-638. ISBN 9058095347.

Blanco, A.; Segura, I.; Cavalaro, S.; Chinchón-Payá, S. and Aguado, A. (2015). "Sand-Cement Concrete in the Century-Old Camarasa Dam." J. Perform. Constr. Facil. , 10.1061/(ASCE)CF.1943-5509.0000823, 04015083.

British Columbia (2011). “Inspection \& Maintenance of Dams”. Dam Safety Guidelines. Canada, 79 p.

Bureau of Reclamation (1997). "Guide to Concrete Repair". U.S. Department of the Interior, Technical service center, $168 \mathrm{p}$.

Calleja, J. (1980). "Empleo racional de los cementos para los diferentes tipos de obras" Materiales de Construcción, 30 (180), pp. 15-74. Doi:10.3989/mc.1980.v30.i180.

Campos, A. (2012). "Análisis numérico de presas de hormigón bajo acciones expansivas". Tesis Doctoral. Escuela Técnica Superior de Ingenieros de Canales, Caminos y Puertos. Universitat Politècnica de Catalunya. Barcelona, $270 \mathrm{p}$.

Carter, J.; Müller-Stöver, I.; Östensen, H.; y Heuck, C. (2005). "Good clinical diagnostic practice”. World Health Organization, Regional Office for the Eastern Mediterranean, 220 p.

Chatterji, S. (1995). "Mechanism of expansion of concrete due to the presence of dead-burnts $\mathrm{CaO}$ and MgO”. Cement and Concrete Research, 25 (1), pp. 51-56. DOI:10.1016/0008-8846(94)00111-B.

Diéz-Cascón, J. y Bueno, F. (2001). "Ingeniería de presas. Presas de fábrica”. 2 tomos. Ed. Universidad de Cantabria. 
Ellingwood, B. and Tekie, P. B. (2000). "Fragility analysis of concrete gravity dams". J. Infrastruct. Syst., 7(2): 41-48.

Fargier, Y.; Fauchard, C.; Mériaux P.; Royet P.; Palma-Lopes, S.; François, D.; Côte, P. y Bretar. F. (2012). "Methodology Applied to the Diagnosis and Monitoring of Dikes and Dams". Novel approaches and their applications in risk assessment. InTech, pp 263 a 289. ISBN: 978-953-51-0519.

Feinstein, A. R. (1967). “Clinical Judgment”. Williams and Wilkins Co. Baltimor, 414 p.

Friedman, H.H. (2001). "Problem-oriented Medical Diagnosis". Lippincott Williams \& Wilkins, 7th edition, Philadelphia, 4470 p. ISBN 0-7817-2909-2.

Gonnerman, H.F.; Learch, W. y Whiteside, T.M. (1953). "Investigations of the hydration expansion characteristics of Portland cements." Bull. 45. Portland Cement Association, Chicago, 181 p.

Groza, O. y Toda, C. (2011). "Defects in concrete dams". Journal of the Audio Engineering Society, Section Civil Engineering Installations, pp. 73-78.

ICOLD (1989). "Exposure of dam concrete to special aggressive waters". Bulletin 71, París.

ICOLD (1991). “Alkali-aggregate reaction in concrete dams”. Bulletin 79, París.

ICOLD (1994). “Ageing of dams and appurtenant Works”. Bulletin 93, París.

ICOLD (1997B). “Concrete dams - Control and treatment of cracks”. Bulletin 102, París.

ICOLD (1997A). "Declaración del ICOLD sobre el medio ambiente”. 16 p.

ICOLD (2011). “The World Register of Dams. Electronical Register”. 2nd Update of 4th editions.

ITCOLD (1999). "Processi di invecchiamento di dighe e loro fondazioni”. Bolletino 7. 89 p.

ITCOLD (2012). "Potenzialità, limiti e possibili sviluppi delle tecniche di identificazione strutturale per la diagnostica delle dighe". $163 \mathrm{p}$.

ITCOLD (1988). "Tecniche e realizzazioni italiane per il monitoraggio delle dighe e delle loro fondazioni”. Bolletino $1.80 \mathrm{p}$.

Johansen V. (1977). "Cocción de clínker de cemento portland en hornos rotatorios" Materiales de Construcción, 27(166-167), 85-101. DOI:10.3989/mc.1977.v27.i166-167.

Kalantarnia, M.; Chouinard, L. and Foltz, S. (2016). "Objective Procedure for Optimization of Inspection and Testing Strategies for Spillways”. J. Infrastruct. Syst., 2016, 22(1): 04015011

Laín, P. (1982). “El diagnóstico médico. Historia y teoría”. Ed. Salvat, Barcelona, 425 p.

Lombardi, G.; Bremen, R. y Ambreg, F. (2001). "Long term behaviour of three arch dams. " Sixth Benchmark Workshop on Numerical Analysis of Dams. ICOLD. Salzburg. pp 1-12.

Martínez Roig, J. M.; Aguado, A.; Agulló, L. y Vázquez, E. (1991). "Diagnosis of the behaviour of the Graus and Tabescán dams”. 7th Intenational Congress on Large Dams. Vienna, pp. 603-617. 
Morgan, W. y Engel, G. (1969). "The Clinical Approach to the Patient". Nueva Editorial Saunders, Philadelphia, 311 p. ASIN: B007T045UA.

New York State-Department of Environmental Conservation (1987). “An Owners Guidance Manual for the Inspection and Maintenance of Dams in New York State". DEC Publication, 50p.

Pardo-Bosch, F. \& Aguado, A. (2015). "Investment priorities for the management of hydraulic structures". Structure and Infrastructure Engineering: Maintenance, Management, Life-Cycle Design and Performance, 11 - 10, 1338 - 1351. doi:10.1080/15732479.2014.964267.

Pardo-Bosch, F. \& Aguado, A. (2016). "Sustainability as the key to prioritize investments in public infrastructures”. Environmental Impact Assessment Review. doi.org/10.1016/ j.eiar. 2016.03.007.

Peyras, L.; Royet, P. y Boissier, D. (2006). "Dam ageing diagnosis and risk analysis: Development of methods to support expert judment". Canadian Geotechnical Journal, 43, pp. 169-186. Doi:10.1139/T05096.

Schnitter, N. (1994). "A History of Dams: The Useful Pyramids". Balkema, London, 266 p. ISBN: 9054101490.

Talavera, J. y Rivas Ruiz, R. (2012). "Del juicio clínico al ensayo clínico”. Revista Médica Instituto Mexicano del Seguro Social. Distrito Federal, México, pp 267-272.

UNEP (2007). “Dams and Development Relevant practices for improved decision-making”. United Nations Environment Programme Dams and Development Project. Nairobi, 177p.

Wu, X. y Qie, Z. (2002). “An applied expert system used in earth dam's fault diagnosis”. Proceedings of the 1rst International Congress on Dam Maintenance and Rehabilitation, Madrid, pp. 223-226.

$\mathrm{Xu}, \mathrm{Y}$. (2011). "Analysis of dam failures and diagnosis of distresses for dam rehabilitation". Doctoral Thesis. The Hong Kong University of Science and Technology. Hong Kong. 317 p. 


\section{LIST OF FIGURE CAPTIONS}

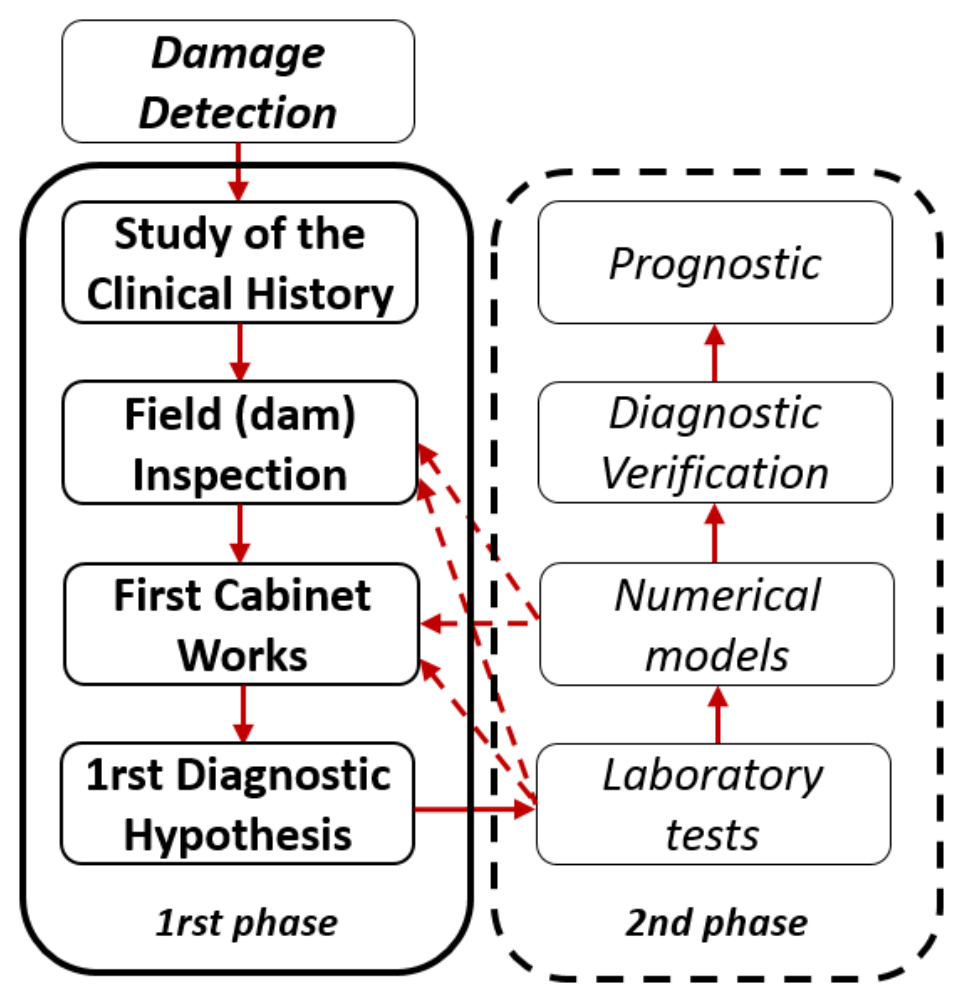

Fig.1.- Diagnostic's phases

a)

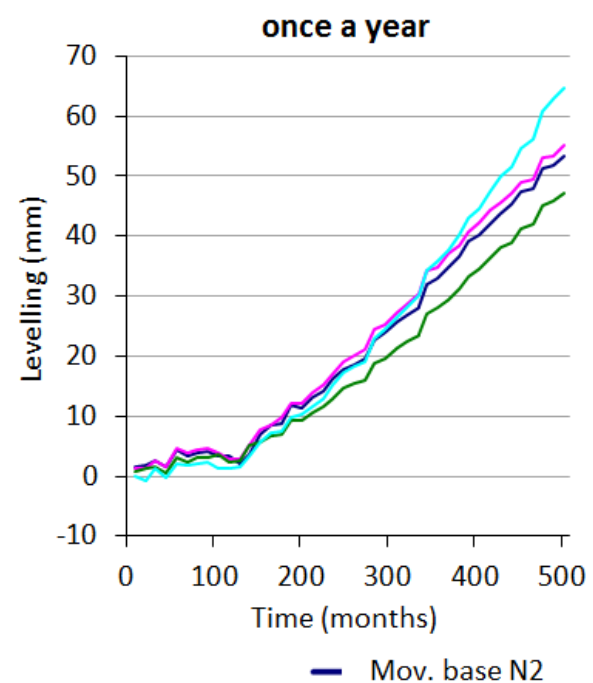

b)

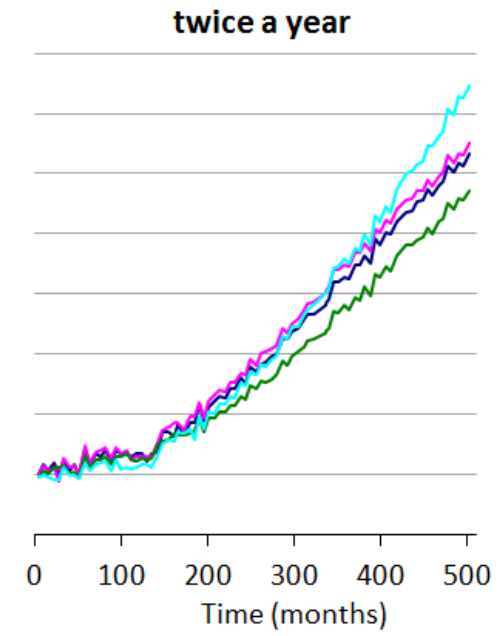

- Mov. base N3 - Mov. base N4 c)

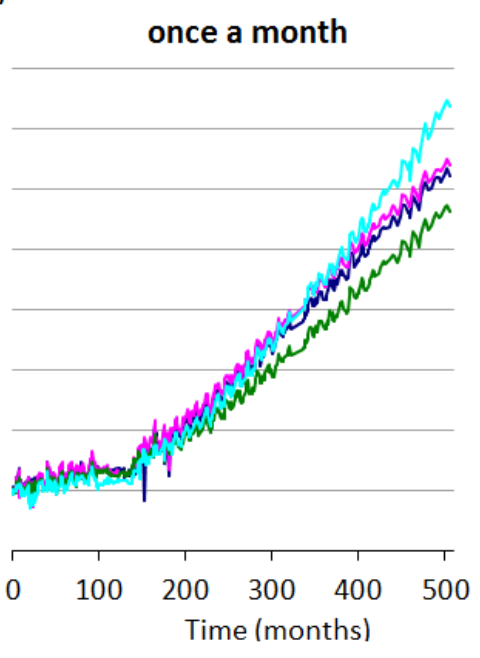

- Mov. base N5

Fig. 2.- Levelling movements measured with different frequencies 

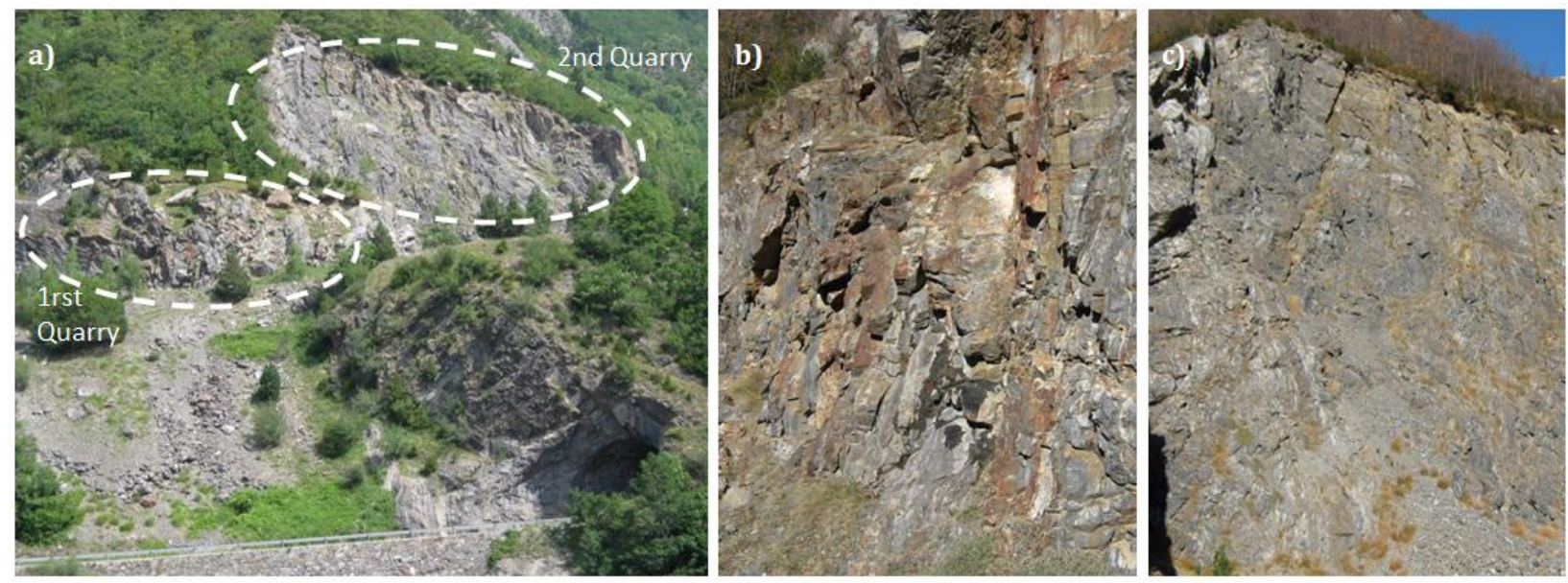

Fig. 3.- Two different quarries used to build the same dam

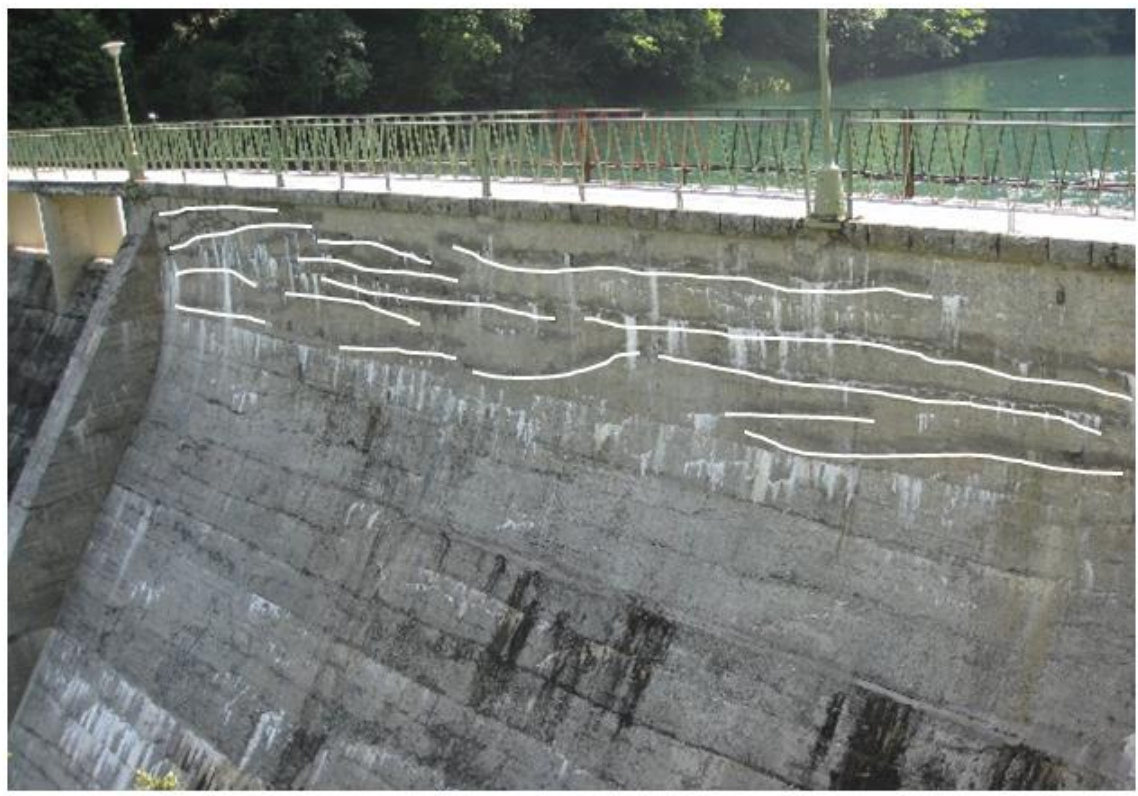

Fig. 4.- Horizontal fissure on a dam body 

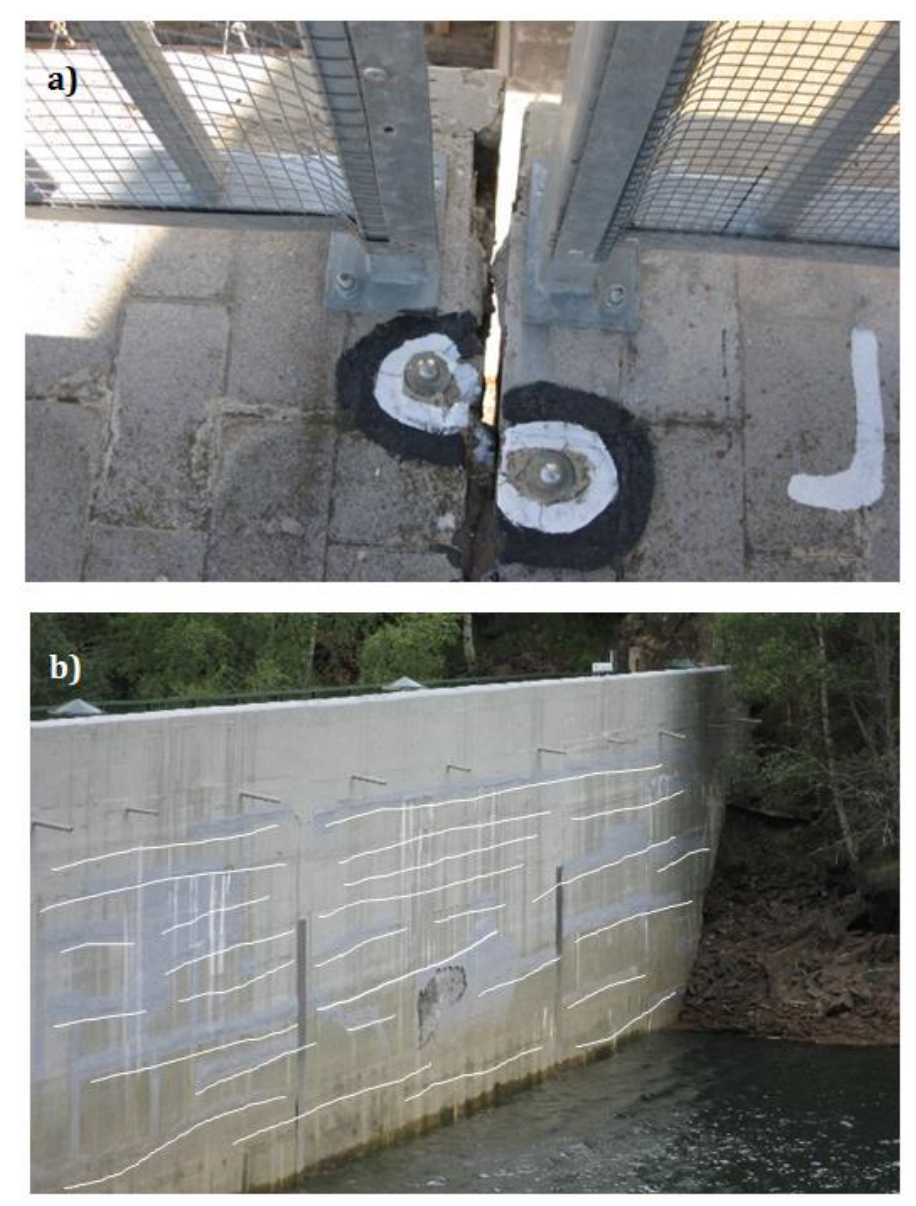

Fig. 5.- Damages in dams: a) remaining movements; b) Fissures upstream face

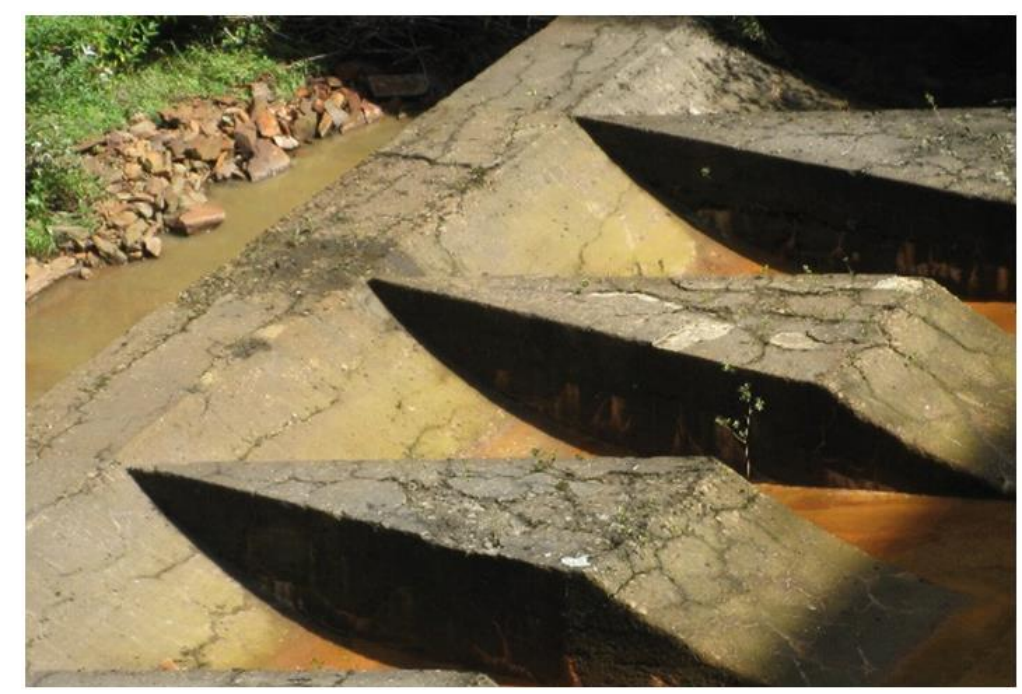

Fig. 6.- Cracks in an annexed structures 


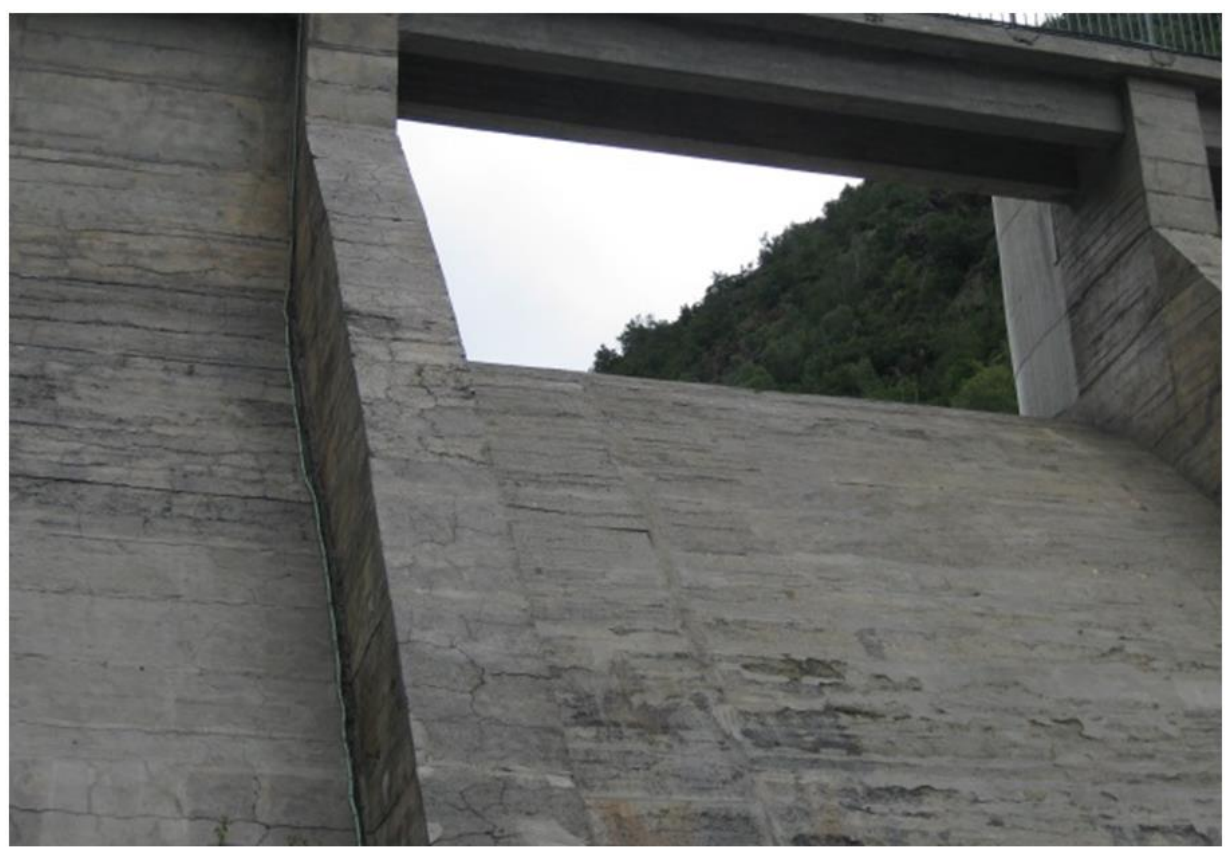

Fig. 7.- Damage in a dam: downstream face body and spillway

a)

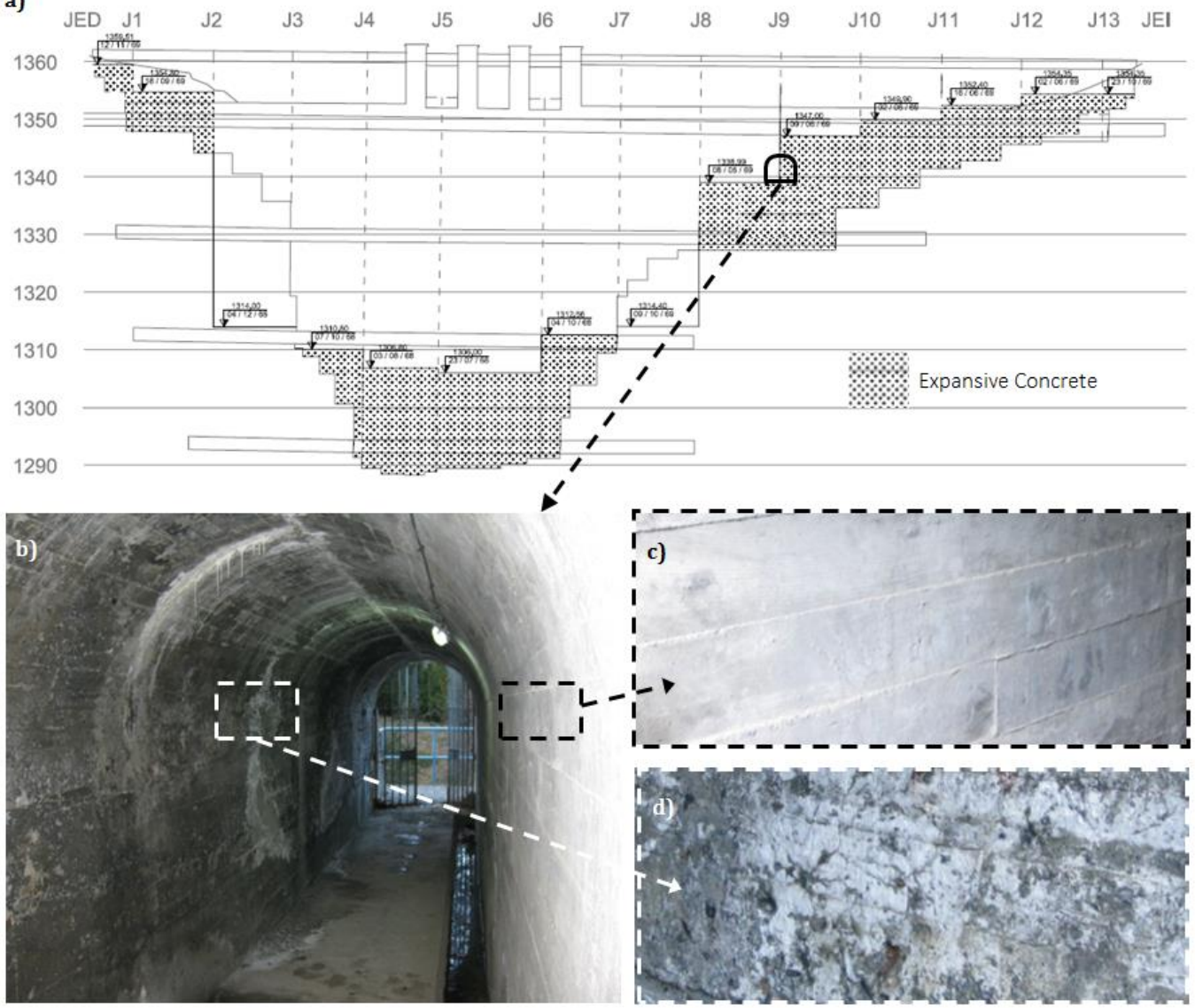

Fig. 8.- Gallery's concrete with different states of conservation 


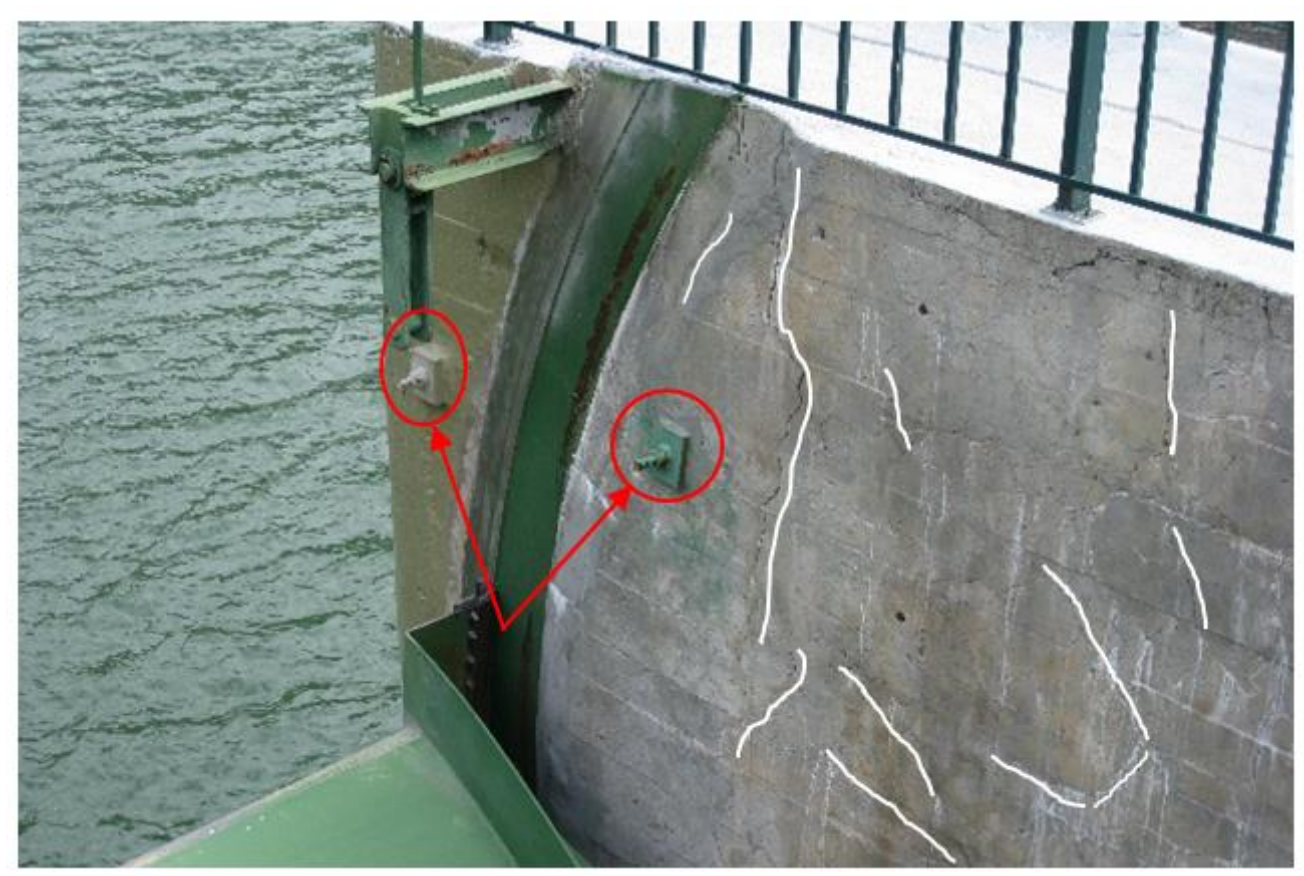

Fig. 9.- Gate area with cracks
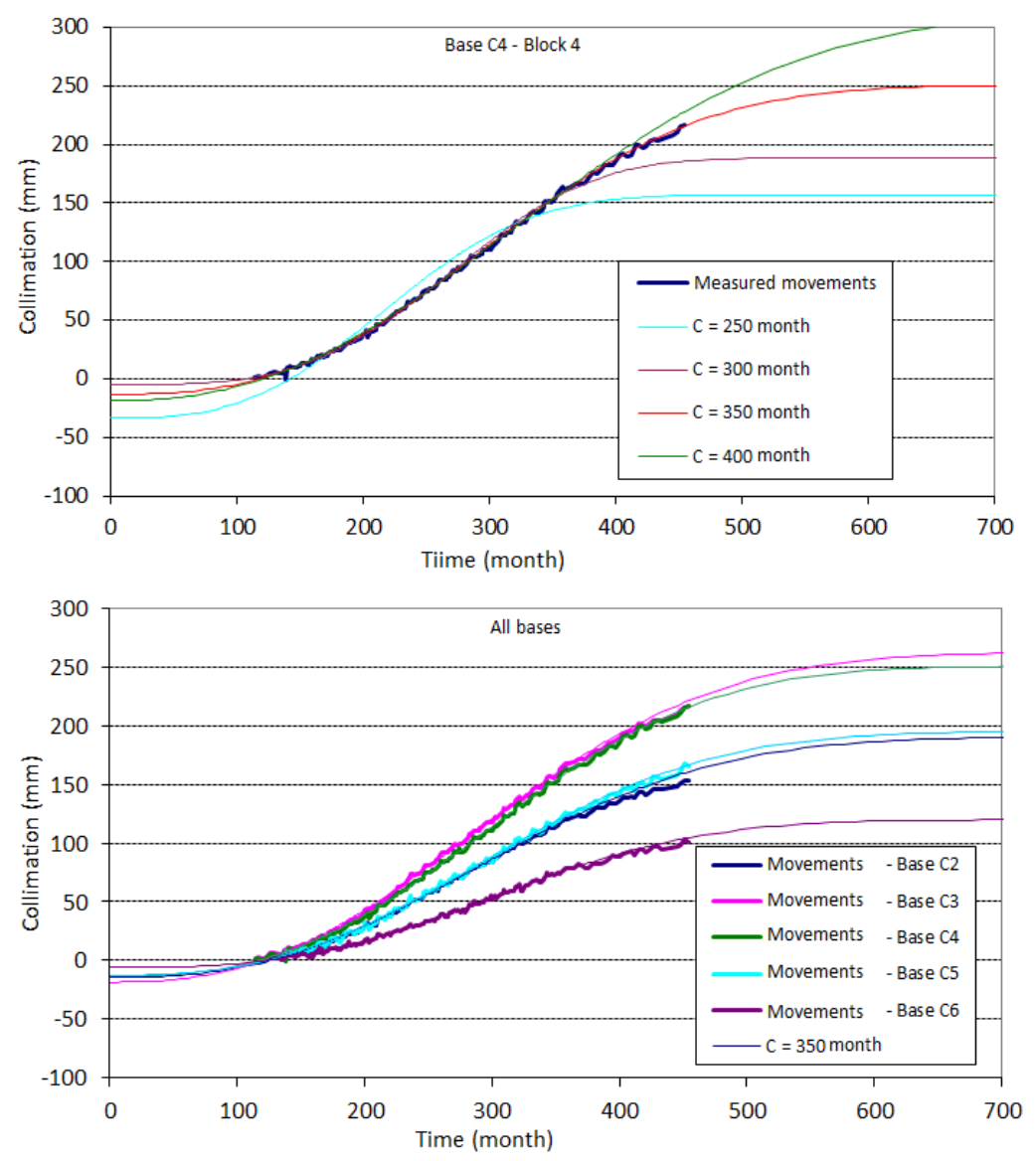

Fig. 10.- Movements adjustments and predictions 


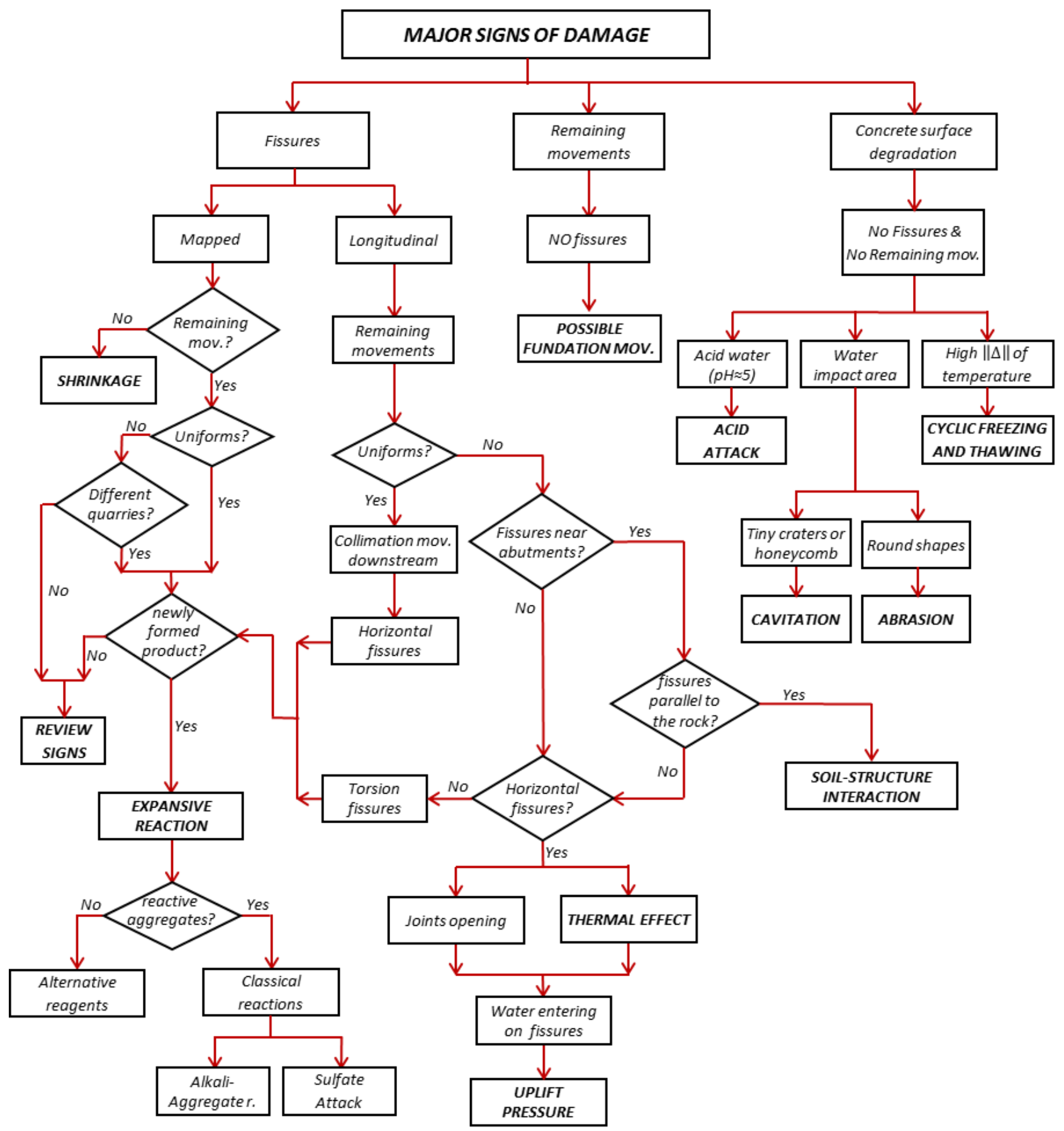

Fig. 11.- Summary table to determine the 1rs diagnostic hypothesis 

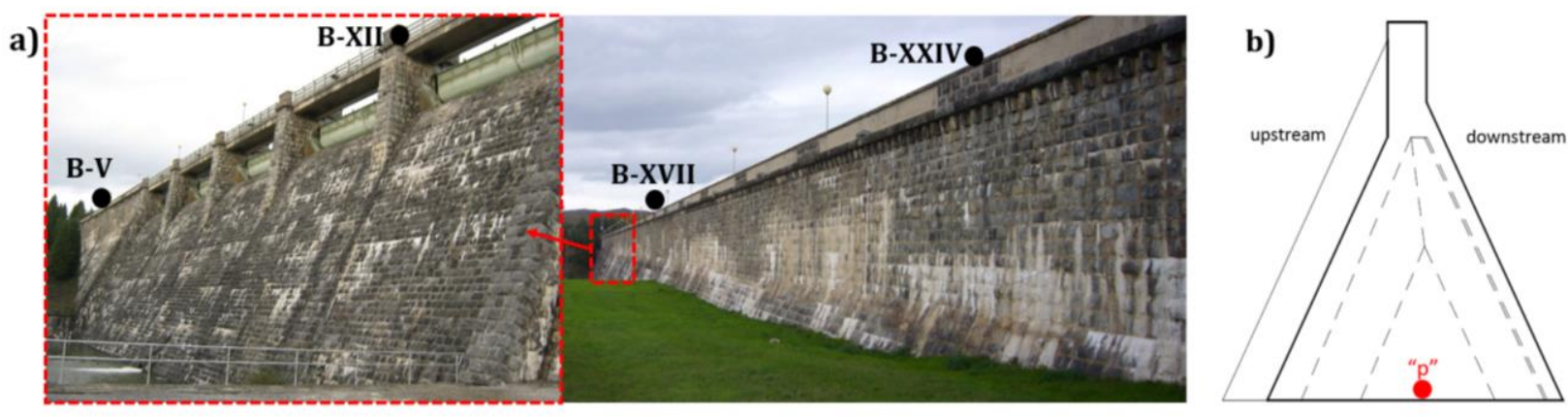

Fig. 12.- Dam's features

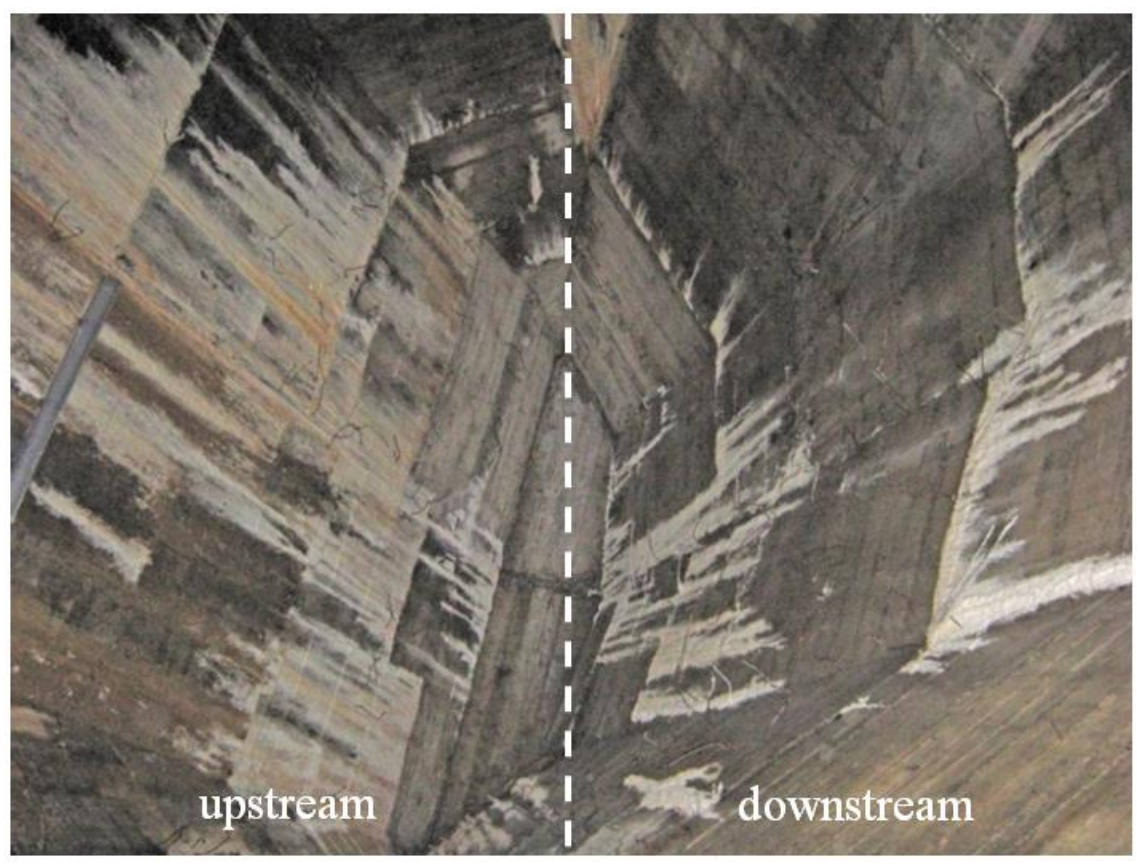

Fig. 13.- Calcium carbonate in joints 
a)

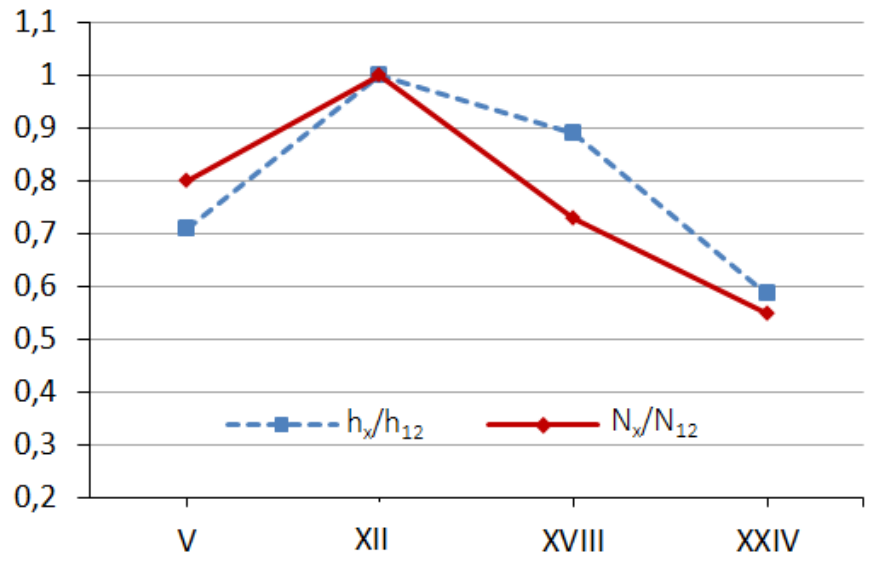

b)

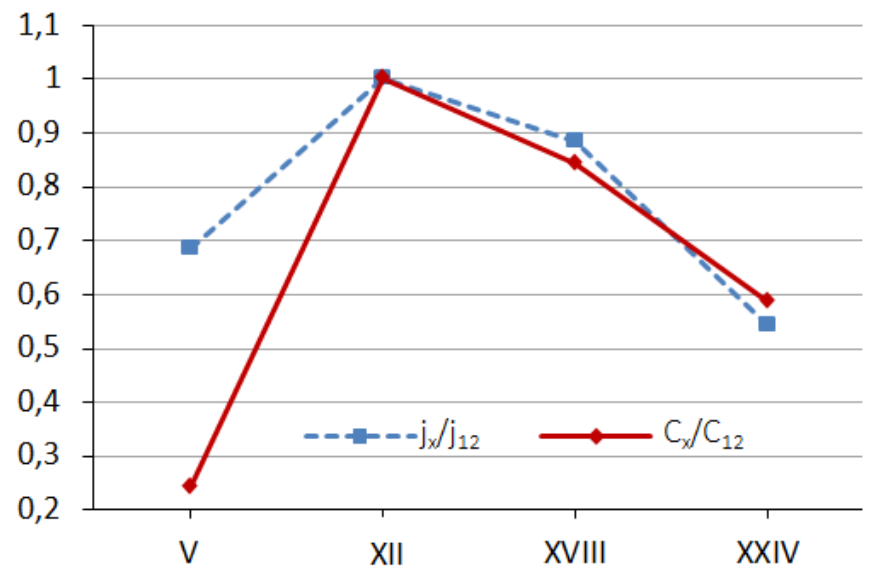

Fig. 14.- Relationship between remnant movements and the geometry of the dam blocks 


\section{TABLES}

Table 1.- Causes of damage to operational concrete dams

\begin{tabular}{|c|c|c|c|}
\hline REASON & SIGN & LOCATION & CONSEQUENCES \\
\hline $\begin{array}{l}\text { Expansive } \\
\text { reaction }\end{array}$ & $\begin{array}{c}\text { Mapped fissures, remaining } \\
\text { movements and reaction products. } \\
\text { Locked mobile elements }\end{array}$ & Any concrete element & $\begin{array}{l}\text { Irreversible process which can } \\
\text { affect vital elements of the } \\
\text { dam }\end{array}$ \\
\hline Acid Attacks & $\begin{array}{l}\text { Concrete surface material loss. } \\
\text { Formation of salt deposits }\end{array}$ & $\begin{array}{c}\text { Dam body, especially around } \\
\text { the edges with water and air } \\
\text { presence }\end{array}$ & Low structural risks \\
\hline $\begin{array}{l}\text { Abrasive } \\
\text { erosion }\end{array}$ & $\begin{array}{c}\text { Thickness loss, smooth concrete } \\
\text { surface and polished coarse } \\
\text { aggregate }\end{array}$ & $\begin{array}{l}\text { Spillways, buffer bowls and } \\
\text { drain tunnels }\end{array}$ & $\begin{array}{c}\text { Minor damage to the stability } \\
\text { of the dam; potential problems } \\
\text { during operation }\end{array}$ \\
\hline $\begin{array}{c}\text { Cavitation } \\
\text { erosion }\end{array}$ & $\begin{array}{l}\text { Random honeycomb. } \\
\text { Noise and vibration }\end{array}$ & $\begin{array}{c}\text { Spillways, discharge } \\
\text { springboard, discharge } \\
\text { tunnels, penstock, teeth of } \\
\text { buffer bowls }\end{array}$ & $\begin{array}{c}\text { Minor damage to the stability } \\
\text { of the dam; potential problems } \\
\text { during operation }\end{array}$ \\
\hline $\begin{array}{l}\text { Cyclic freezing } \\
\text { and thawing }\end{array}$ & $\begin{array}{l}\text { Extensions on the } \\
\text { concrete surface }\end{array}$ & $\begin{array}{c}\text { Downstream face, crest } \\
\text { surface and spillways slabs }\end{array}$ & Low structural risks \\
\hline Thermal effect & $\begin{array}{l}\text { Fissures (without predominant } \\
\text { directions) }\end{array}$ & $\begin{array}{l}\text { Downstream face (mostly) } \\
\text { and upstream face }\end{array}$ & Significant structural risks \\
\hline $\begin{array}{c}\text { Rock mass } \\
\text { deformation }\end{array}$ & $\begin{array}{l}\text { Longitudinal fissures; remaining } \\
\text { movements }\end{array}$ & Dam body and upper galleries & Significant structural risks \\
\hline $\begin{array}{c}\text { Uplift } \\
\text { pressure }\end{array}$ & $\begin{array}{l}\text { Opening fissures and construction } \\
\text { joints; remaining movements }\end{array}$ & Dam body & Significant structural risks \\
\hline
\end{tabular}


Table 2.- Activities of field (dam) inspection

\begin{tabular}{|c|c|c|c|c|}
\hline Phase & Study & Zone & \multicolumn{2}{|l|}{ Signs to analyze... } \\
\hline \multirow{6}{*}{$\begin{array}{c}\text { Field } \\
\text { inspection }\end{array}$} & \multirow{2}{*}{$\begin{array}{l}\text { Geological } \\
\text { formation }\end{array}$} & Quarry & \multicolumn{2}{|l|}{ Reactive aggregate and surface degradation } \\
\hline & & Abutments & $\begin{array}{l}\text { Discontinuities, intrusions, newly formed } \\
\text { products and surface degradation }\end{array}$ & \multirow{5}{*}{ cracks } \\
\hline & \multicolumn{2}{|c|}{ Annexed structures } & $\begin{array}{l}\text { Tiny craters, reinforcement corrosion, } \\
\text { moisture, biological growth, etc. }\end{array}$ & \\
\hline & \multirow{2}{*}{ Dam body } & Exterior & $\begin{array}{c}\text { Remaining movements and concrete degradation } \\
\text { (partial or local breaks, surface degradation, opening } \\
\text { of construction joints, stains, leaks, etc.) }\end{array}$ & \\
\hline & & Interior & $\begin{array}{c}\text { Concrete degradation (leaks, leachate products, newly } \\
\text { formed reaction products, concrete surface } \\
\text { deterioration, etc.) }\end{array}$ & \\
\hline & \multicolumn{2}{|c|}{ Mobile elements } & Concrete degradation and misalignment & \\
\hline
\end{tabular}

Table 3.- Data for the study

\begin{tabular}{cccccccccccc}
\hline Base & Block & $\mathbf{h}(\mathbf{m})$ & $\mathbf{b}_{\mathbf{M}}(\mathbf{m})$ & $\mathbf{b}_{\text {eq}}(\mathbf{m})$ & $\mathbf{j}=\mathbf{h}^{2} / \mathbf{b}_{\text {eq }}$ & $\mathbf{C}(\mathbf{m m})$ & $\mathbf{N}(\mathbf{m m})$ & $\mathbf{h} / \mathbf{h}_{12}$ & $\mathbf{N} / \mathbf{N}_{\mathbf{1 2}}$ & $\mathbf{j} / \mathbf{j}_{12}$ & $\mathbf{C} / \mathbf{C}_{\mathbf{1 2}}$ \\
\hline N5-C13 & V & 21,00 & 14,70 & 21,3 & 20,70 & 13,62 & $-1,17$ & $\mathbf{0 , 7 0}$ & $\mathbf{0 , 7 9}$ & $\mathbf{0 , 6 8}$ & $\mathbf{0 , 2 4}$ \\
\hline N11-C7 & XII & 29,60 & 21,50 & 29,00 & 30,21 & 17,01 & $-4,82$ & $\mathbf{1 , 0 0}$ & $\mathbf{1 , 0 0}$ & $\mathbf{1 , 0 0}$ & $\mathbf{1 , 0 0}$ \\
\hline N14-C4 & XVIII & 26,30 & 18,70 & 25,88 & 26,73 & 10,85 & $-4,07$ & $\mathbf{0 , 8 8}$ & $\mathbf{0 , 7 2}$ & $\mathbf{0 , 8 8}$ & $\mathbf{0 , 8 4}$ \\
\hline N17-C1 & XXIV & 17,30 & 12,00 & 18,22 & 16,43 & 9,34 & $-2,83$ & $\mathbf{0 , 5 8}$ & $\mathbf{0 , 5 4}$ & $\mathbf{0 , 5 4}$ & $\mathbf{0 , 5 8}$ \\
\hline \multicolumn{7}{c}{$b_{m}=4,5 m$ for all blocks }
\end{tabular}

$X / X_{\mathrm{t}}=$ Variable $X$ of block $i$, normalized with the variable $X$ of the block $t$ 